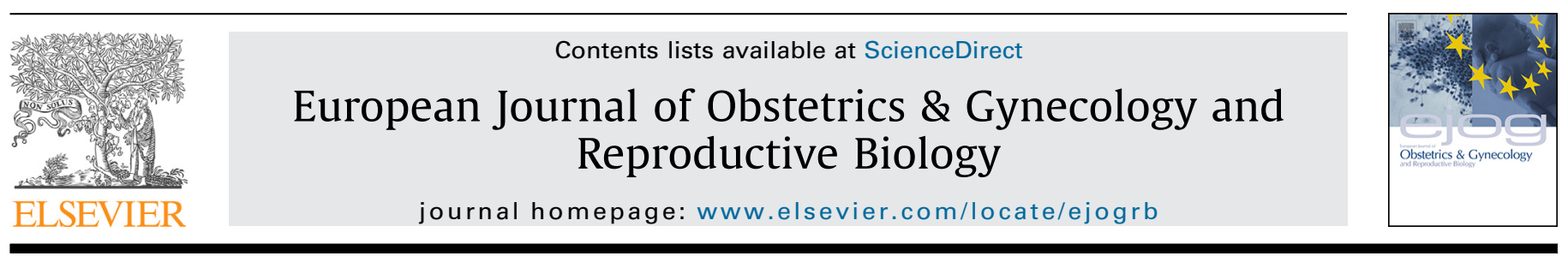

Full length article

\title{
Maternal and neonatal outcomes according to gestational weight gain in twin pregnancies: Are the Institute of Medicine guidelines associated with better outcomes?
}

\author{
Océane Pécheux ${ }^{\mathrm{a}, *}$, Charles Garabedian ${ }^{\mathrm{a}, \mathrm{b}}$, Elodie Drumez ${ }^{\mathrm{c}}$, Sarah Mizrahi ${ }^{\mathrm{a}}$, \\ Sophie Cordiez ${ }^{\mathrm{a}}$, Sophie Deltombe ${ }^{\mathrm{a}}$, Philippe Deruelle ${ }^{\mathrm{a}, \mathrm{b}}$ \\ a Centre Hospitalier Régional Universitaire de Lille, Hôpital Jeanne de Flandre, 2 Avenue Oscar Lambret, 59000, Lille, France \\ b Université Lille2, CHRU Lille, EA 4489, Environnement Périnatal et Santé, F-59000, Lille, France \\ ${ }^{\mathrm{c}}$ Biostatistics, Department of Biostatistics, Univ. Lille, CHU Lille, EA 2694 - Santé publique: épidémiologie et qualité des soins, F-59000, Lille, France
}

\section{A R T I C L E I N F O}

\section{Article history:}

Received 14 November 2018

Received in revised form 6 January 2019

Accepted 8 January 2019

\section{Keywords:}

Twin

Gestational weight gain

Birth weight

Preeclampsia

Prematurity

\begin{abstract}
A B S T R A C T
Objective: The Institute of Medicine (IOM) recommended a gestational weight gain for full-term twin pregnancies of 17-25 kg for normal Body mass Index patients', and characterize its guidelines on during twin pregnancies as "provisional". Indeed, they are exclusively based on observational epidemiological data.

The objective of this study was to investigate whether the IOM's gestational weight gain guidelines are optimal for maternal and neonatal.

Outcomes study design: We included all consecutive twin pregnancies delivering two live births retrospectively. Monoamniotic pregnancies, major congenital abnormalities, twin-to-twin transfusion syndrome, patients with missing gestational weight gain data in the last month before delivery, and patients with a body mass index $(\mathrm{BMI}) \leq 18.5$ were excluded. To control for gestational length, we divided the total weight gain by the gestational age in weeks at the last weight measurement to obtain the weight gain per week. Patients were classified as having low gestational weight gain, adequate gestational weight gain, or excessive gestational weight gain, with the results adjusted for BMI and tobacco use. Results: There were 878 patients in our level-III university hospital maternity ward who met the inclusion criteria in 1997-2013. Excessive gestational weight gain women had greater rates of preeclampsia than adequate gestational weight gain women did. Low gestational weight gain women showed a lower rate of gestational hypertension than AGWG women did. Delivery before 37 weeks of gestation (26.9\% vs. 17.3\%, $\mathrm{p}=0.009$ ), birth weight $<2500 \mathrm{~g}$, respiratory distress syndrome, and transfer to the neonatal intensive care unit were more frequent in the LGWG group compared with the AGWG group. Apgar score $<7$ at 5 min were more frequent in the EGWG group.

Conclusion: Adequate gestational weight gain was associated with better outcomes. Our results suggest that the IOM guidelines for twin pregnancy are appropriate and therefore should be routinely used.
\end{abstract}

(c) 2019 Elsevier B.V. All rights reserved.

\section{Introduction}

Twin gestations are a disproportionally significant factor in perinatal morbidity and mortality [1], as 60\% of twins are born preterm and $25 \%$ have very low birth weight [2,3]. They are involved in high rates of preeclampsia, intrauterine growth restriction (IUGR), cesarean section delivery, and fetal [4] and neonatal death [3]. The number of twin gestations is dramatically

\footnotetext{
* Corresponding author at: CHRU Jeanne de Flandre, Avenue Oscar Lambret, 59000, Lille, France.

E-mail address: oceane-pecheux@hotmail.fr (O. Pécheux).
}

rising, especially with assisted reproductive technology [5]. Issues surrounding twins' antepartum care and risk reduction are becoming of paramount importance.

Inappropriate gestational weight gain (GWG) result in significant consequences for singletons, justifying a particular interest. Indeed, an excessive GWG is responsible of elevated rates of macrosomia and caesarean sections, and of long term weight retention for the mother and even the child [6-8]. At the opposite, an insufficient GWG increases preterm births, IUGR and early mortality [6-8].

GWG is higher for twin pregnancies than for singletons [9], thus this population require specific recommendations. After the Institute of Medicine (IOM) published its recommendations for GWG in twin pregnancies in 1990 [10], further studies have 
demonstrated that, similar to singletons, GWG depends on the prepregnancy body mass index (BMI) [11,12]. Therefore, the IOM revised its guidelines in 2009 [13]. The recommended GWGs for full-term twin pregnancies are 17-25 $\mathrm{kg}$ (37-54 lbs.) for women in the normal weight category (BMI 18.5-24.9), 14-23 kg for women in the overweight category (BMI 25.0-29.9), and 11-19 kg for obese women (BMI > 30) [13,14]. Nevertheless, the IOM referred to these guidelines as "provisional," specifying that they are based only on observational epidemiological data (25th-75th percentiles of GWG per BMI group $\geq 37$ weeks of amenorrhea with mean birth weight $\geq 2500 \mathrm{~g}$ ); this means that they do not consider pregnancy outcomes.

Most of the available literature on this topic focuses on fetal growth and has shown a positive association between GWG and birth weight [11,15-21]. However, this effect has not shown constant statistical results, mainly due to small sample sizes, especially when the results are stratified by prepregnancy BMI. Likewise, the authors do not always control for gestational duration, which is a major confounding factor $[12,22]$, and they sometimes choose to exclude preterm birth to avoid this issue, thereby excluding an important proportion of the patients [16,23], especially those with complications. In addition, there is a lack of data on the effects of excessive GWG (EGWG), as most studies have focused on the link between low GWG (LGWG) and low birth weight [15,24]. Moreover, only a few studies have examined other outcomes, such as preterm birth, gestational diabetes, or hypertensive disorders, and their findings are inconsistent. In addition, many studies were performed before 2009 , and they did not specifically study outcomes regarding the IOM recommendations $[12,25,26,26]$.

The points outlined above show that there is a lack of clinical evidence in the field [27], but GWG appears to be linked with obstetrics outcomes. Determination of the optimal GWG in twin pregnancies is an interesting topic, as it is a modifiable factor and has a high potential for intervention. Indeed, Phelan et al. reported that only $41.7 \%$ of women reported receiving weight gain advice from their practitioner [28], although for singleton pregnancies nutritional and activity interventions have been successful in prior trials in reducing the rate of excessive GWG [29,30].

The main objective of this work was to determine whether the IOM's current guidelines for weight gain in twin pregnancies, according to maternal prepregnancy BMI, have an impact on perinatal outcomes.

\section{Material and methods}

We retrospectively included all consecutive twin pregnancies who delivered in a level-III university hospital maternity ward between 1997 and 2013. The study protocol was approved by the Ethics Committee for Research in Obstetrics and Gynecology of the French National College of Obstetricians and Gynecologists (CNGOF; CEROG OBS 2014-04-02).

We considered all twin gestations with two live born infants delivered after 23 weeks and 6 days of amenorrhea where the mothers had a documented prepregnancy BMI, without twin-totwin transfusion syndrome. The prepregnancy BMI was calculated using self-reported height and weight at the first antenatal visit and categorized according to the World Health Organization's definition. Normal BMI was defined as a BMI of 18.5-24.5, overweight as 25-29.5, and obesity as 30 or greater. The gestational weight change was calculated by subtracting the maternal prepregnancy weight from the weight at delivery, or if not available, the weight at the last prenatal visit. Exclusion criteria included pregnancies complicated by major fetal anomalies, and monoamnionicity. We also excluded women with a pre-pregnancy BMI less than $18.5 \mathrm{~kg} / \mathrm{m}$ [2] (underweight), as the IOM has not yet made weight gain recommendations in this population, and patients without any weight report less than a month before their delivery.

As suggested by many authors previously [15,17-19,33,34], and because the IOM weight gain recommendations are for women who deliver at 37 weeks or after, it would not be appropriate to compare the total GWG in women who delivered at earlier gestational ages. Therefore, to control for gestational age at delivery, we divided the total weight gain by the gestational age in weeks at the last weight measurement to obtain the weight gain per week. We then divided the IOM lower limit of adequate weight gain at 37-42 weeks by 37 to determine the IOM recommended weight gain per week. For normal-BMI women, this was $0.46-0.68 \mathrm{~kg} /$ week; for overweight women, it was $0.36-0.62 \mathrm{~kg} /$ week; and for obese women, it was $0.3-$ $0.51 \mathrm{~kg} /$ week. Then, we compared obstetrical and neonatal outcomes between groups of women categorized according to the IOM guidelines' matched cutoffs. In fact, we compared the adequate GWG (AGWG) group with women who exceeded the recommended GWG (EGWG), and women in whom the weight gain was below the IOM guidelines (low GWG, LGWG).

Chorionicity was determined based on the first-trimester ultrasound assessment of the dividing membrane characteristics (absence of the "twin peak" sign and presence of a thin dividing membrane) and confirmed by postpartum examination of the placenta and intertwined membrane.

All twin pregnancies were monitored according to the French guidelines [35]. Accordingly, uncomplicated monochorionic pregnancies were delivered between 36 and 39 weeks of gestation and dichorionic ones between 38 and 40 weeks [35]. Obstetrical complications included gestational hypertension, preeclampsia (diagnosis made using standard criteria [36]), gestational diabetes mellitus (GDM), cholestasis, placenta previa, premature rupture of membranes, premature delivery threats, instrumental deliveries, cesarean sections, and severe $(>1 \mathrm{~L})$ postpartum hemorrhage.

For neonates, we considered premature birth before 37 and 34 weeks' gestation, birth weight, arterial blood cord $\mathrm{pH}<7.10$, Apgar score $<7$ at $5 \mathrm{~min}$, transfer to neonatal intensive care unit (NICU), respiratory distress, neonatal sepsis, and death. Small for gestational age was defined as birth weight <10th centile according to the curves used in our department [37].

Data were collected using the CLINSIGHT software (Version $6.2 .300,2011$ ). Qualitative variables were described in terms of frequency and percentage, categorical variables as the mean (standard deviation) for age and median (interquartile range) for BMI. The normality of the quantitative variables was graphically checked and tested using the Shapiro-Wilk test. Patients' characteristics and main complications were compared between the included and excluded patients using the chi-square test for categorical variables and Student $t$-test for age. The patients' characteristics were compared between the three GWG groups using chi-square tests for categorical variables and an analysis of variance for age. Pregnancy and neonatal outcomes were compared using unadjusted and adjusted tests. For unadjusted comparisons, the three GWG groups were compared using chisquare tests, and for adjusted comparisons, logistic regression analyses were performed. The multivariable model was adjusted for pregestational BMI and smoking. Post hoc pairwise comparisons with the reference group (AGWG) were performed using the Bonferroni correction. Statistical testing was done at a two-tailed $\alpha$ level of 0.05. Data were analyzed using the SAS software package, release 9.4 (SAS Institute, Cary, NC).

\section{Results}

We included 878 women (Fig. 1). According to the prepregnancy BMI categories, there were 621 normal weight women (71\%), 168 overweight women (19\%), and 88 obese women (10\%). 


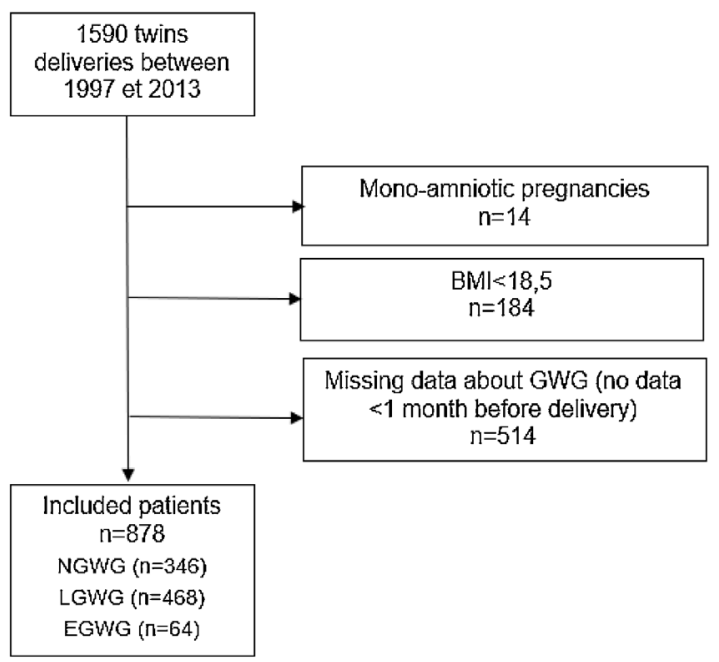

BMI: body mass index

GWG: gestational weight gain ( $N=$ normal; $L=10 w ; E=e x c e s s i v e)$

Fig. 1. Flow-chart of the study.

Among them, we counted 346 AGWG, 468 LGWG, and 64 EGWG patients.

In comparison with women from the AGWG reference group, women in the EGWG group were more likely smokers (23.4\% in the EGWG group vs. $12.1 \%$ in the AGWG group), and they had a higher preconceptional BMI than women in the AGWG group did. Other patient characteristics were similar between the groups (Table 1 ). Table 3 (Supplementary material) shows that the included and excluded patients' characteristics were not statistically different.

Maternal and neonatal complications are reported in Table 2. Compared with AGWG women, LGWG women showed a lower rate of gestational hypertension (adjusted p value $=0001$ ). Likewise, EGWG women exhibited increased rates of preeclampsia compared with AGWG women. The LGWG group compared with the AGWG group showed more deliveries before 37 weeks of gestation ( $26.9 \%$ vs. $17.3 \%, p=0.009)$, birth weight $<2500$ g $(77.5 \%$ vs. $64.2 \%$, $\mathrm{p}<0.0001$ ), respiratory distress syndrome, and transfer to the NICU. Nevertheless, neonates from EGWG patients more often showed Apgar scores <7 at $5 \mathrm{~min}(15.6 \%$ vs. $7.2 \%, \mathrm{p}=0049)$.

There were no other statistically significant differences between the groups.

\section{Discussion}

We sought to investigate the effects of inadequate GWG on twin pregnancies according to the IOM classification (2009), considering the gestational age at delivery. In summary, we found more preeclampsia with EGWG and less gestational hypertension for LGWG compared with AGWG. IUGR, preterm birth and its usual complications were more frequent for LGWG women.

We observed that a high majority of AGWG and LGWG patients were included in the study; only $7.3 \%$ of the women were EGWG patients, who are supposed to constitute the full upper quartile. This may partly be due to our integration of preterm births and birth weights $<2500 \mathrm{~g}$, as the IOM recommendations were generated from the 25th-75th percentile of GWG for term pregnancies delivering twins $>2500 \mathrm{~g}$. However, this was not the case in other published studies [17,18,33,34]. Because most of the studies are from North America, this difference in the distribution could reflect European patients' characteristics. We also observed than only $10 \%$ of our patients were obese before pregnancy, a lower rate than expected. Indeed, $38 \%$ of the women wordwide are obese [39], but only 15\% in France [40]. McKeating et al., about pregnant women, reported a $8.6 \%$ obese rate in the 13 European Union Accession countries and a $15.4 \%$ rate of the Original European Union countries, according [38], thus our rate is in between. It would be interesting to know if obese women are less likely to get a twin pregnancies, because of fertility issues maybe.

One of the main strengths of our study is that we adjusted our results according to the prepregnancy BMI. We also controlled our results for gestational duration, dividing the total GWG by gestational duration, to avoid bias due to the strong correlation between GWG and gestational duration. Indeed, the IOM recommendations were established for "total weight gain". However, women with longer pregnancies have more time to gain weight, and GWG is not linear throughout pregnancy. GWG during the first half of pregnancy is usually lower than in the second half [41]. Assumption of a linear weight gain pattern may have resulted in the incorrect conclusion that women delivering preterm will have lower rates of gain overall than those who deliver at a later gestational age [42].

Moreover, we decided to adjust the birth weight for gestational age. Using absolute birth weights is problematic because this cannot separate the neonates who are small due to IUGR and those who are small due to preterm birth.

We found more deliveries before 37 and 34 weeks, and birth weights $<2500 \mathrm{~g}$ and $<10^{\text {th }}$ percentile for the LGWG patients. The evident correlation between GWG and birth weight/prematurity

Table 1

Patients' characteristics according to their gestational weight gain.

\begin{tabular}{|c|c|c|c|c|c|}
\hline & Total $(\mathrm{n}=878)$ & AGWG $(n=346)$ & LGWG $(n=468)$ & EGWG $(n=64)$ & $\mathrm{p}$ \\
\hline Age, mean (SD) (years) & $30.5(4.9)$ & $30.7(4.5)$ & $30.5(5.1)$ & $29.2(4.6)$ & 0.07 \\
\hline Chorionicity & & & & & 0.39 \\
\hline Bichorial & $728(83.0)$ & $293(84.7)$ & $385(82.4)$ & $50(78.1)$ & \\
\hline Monochorial diamniotic & $149(17.0)$ & $53(15.3)$ & $82(17.6)$ & $14(21.9)$ & \\
\hline Pregestational hypertension & $3(2.0)$ & $1(1.8)$ & $1(1.3)$ & $1(7.7)$ & NA \\
\hline Pregestational diabetes mellitus & $3(2.1)$ & $1(1.8)$ & $2(2.6)$ & 0 & NA \\
\hline Nulliparity & $444(50.6)$ & $180(52.0)$ & $232(49.6)$ & $32(50.0)$ & 0.78 \\
\hline Smoking & $118(13.5)$ & $42(12.1)^{b}$ & $61(13.1)$ & $15(23.4)^{b}$ & 0.049 \\
\hline Medically Assisted Reproduction & $340(38.8)$ & $134(38.8)$ & $190(40.7)$ & $16(25.0)$ & 0.054 \\
\hline History of cesarean & $77(9.7)$ & $21(6.7)$ & $50(11.9)$ & $6(10.0)$ & 0.060 \\
\hline BMI, median (IQR) & 22.5 (20.6 to 25.7$)$ & 22.6 (20.8 to 25.5$) \mathrm{b}$ & $22.2(20.2$ to 25.4$)$ & 25.0 (22.0 to 29.0$) \mathrm{b}$ & 0.001 \\
\hline$<25$ & $621(70.8)$ & $246(71.1)$ & $344(73.7)$ & $31(48.4)$ & \\
\hline $25-30$ & $168(19.2)$ & $73(21.1)$ & $77(16.5)$ & $18(28.1)$ & \\
\hline$>30$ & $88(10.0)$ & $27(7.8)$ & $46(9.9)$ & $15(23.4)$ & \\
\hline
\end{tabular}

Values are number (percentage) unless otherwise indicated.

a. b identify the significant pairwise post-hoc comparisons with reference group (NGWG) after Bonferroni's correction.

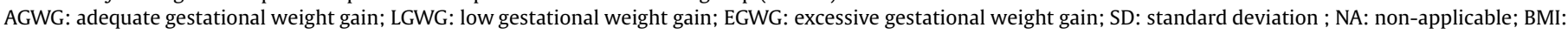
body mass index; IQR: interquartile range. 
Table 2

Included and excluded patients' characteristics.

\begin{tabular}{|c|c|c|c|c|c|c|}
\hline & \multirow{2}{*}{$\begin{array}{l}\text { AGWG }(\mathrm{n}=346) \\
\mathrm{n}(\%)\end{array}$} & \multicolumn{2}{|c|}{ LGWG $(n=468)$} & \multicolumn{2}{|c|}{ EGWG $(n=64)$} & \multirow[t]{2}{*}{ P-value ${ }^{*}$} \\
\hline & & $\mathrm{n}(\%)$ & OR $(95 \% \mathrm{CI})$ & $\mathrm{n}(\%)$ & OR $(95 \% \mathrm{CI})$ & \\
\hline Gestational hypertension & $26(7.5)$ & $11(2.4)$ & $0.28(0.14 \text { to } 0.59)^{\mathrm{a}}$ & $9(14.3)$ & $1.67(0.71$ to 3.90$)$ & 0.001 \\
\hline Preeclampsia & $21(6.1)$ & $14(3.0)$ & $0.48(0.24$ to 0.97$)$ & $10(15.6)$ & $2.60(1.14 \text { to } 5.96)^{b}$ & 0.001 \\
\hline Cholestasis & $5(1.5)$ & $19(4.3)$ & NA & 0 & NA & NA \\
\hline Gestational diabetes mellitus & $94(30.6)$ & $151(36.9)$ & $1.33(0.97$ to 1.83$)$ & $22(39.3)$ & $1.43(0.78$ to 2.61$)$ & 0.18 \\
\hline Placenta praevia & $3(2.6)$ & $2(1.2)$ & NA & 0 & NA & NA \\
\hline Post-partum hemorrhage $>1000 \mathrm{cc}$ & $35(11.2)$ & $39(9.2)$ & $0.82(0.50$ to 1.32$)$ & $10(17.2)$ & $1.80(0.82$ to 3.97$)$ & 0.13 \\
\hline Premature delivery threat & $209(60.6)$ & $327(70.0)$ & $1.55(1.16 \text { to } 2.08)^{a}$ & $37(57.8)$ & $0.97(0.56$ to 1.67$)$ & 0.009 \\
\hline Delivery $<37$ weeks & $60(17.3)$ & $126(26.9)$ & $1.73(1.22 \text { to } 2.44)^{a}$ & $15(23.4)$ & $1.31(0.68$ to 2.53$)$ & 0.009 \\
\hline Delivery $<34$ weeks & $18(5.2)$ & $48(10.3)$ & $2.07(1.18 \text { to } 3.64)^{a}$ & $6(9.4)$ & $1.54(0.57$ to 4.12$)$ & 0.040 \\
\hline PROM & $61(17.7)$ & $95(20.5)$ & $1.22(0.86$ to 1.75$)$ & $12(18.8)$ & $1.03(0.51$ to 2.07$)$ & 0.53 \\
\hline Instrumental delivery & $171(58.7)$ & $235(58.5)$ & $0.99(0.73$ to 1.35$)$ & $37(67.3)$ & $1.26(0.68$ to 2.36$)$ & 0.73 \\
\hline Cesarean delivery & $108(31.3)$ & $149(31.8)$ & $1.02(0.75$ to 1.38$)$ & $22(34.4)$ & $1.04(0.58$ to 1.84$)$ & 0.99 \\
\hline Birth weight $<2500 \mathrm{~g}$ & $222(64.2)$ & $362(77.5)$ & $1.92(1.41 \text { to } 6.62)^{a}$ & $40(62.5)$ & $0.87(0.50$ to 1.54$)$ & $<0.0001$ \\
\hline Birth weight $<10$ th percentile & $165(48.3)$ & $235(50.8)$ & $1.11(0.84$ to 1.57$)$ & $22(34.4)$ & $0.54(0.31$ to 0.95$)$ & 0.038 \\
\hline Respiratory distress & $53(15.5)$ & $106(23.0)$ & $1.63(1.13 \text { to } 2.36)^{a}$ & $15(23.4)$ & $1.50(0.77$ to 2.91$)$ & 0.032 \\
\hline $\mathrm{pH}<7.10$ (arterial blood cord) & $7(8.1)$ & $13(9.8)$ & $1.23(0.46$ to 3.24$)$ & $1(7.1)$ & $0.75(0.08$ to 7.07$)$ & 0.86 \\
\hline Apgar $<7$ at 5 minutes & $25(7.2)$ & $41(8.8)$ & $1.25(0.74$ to 2.10$)$ & $10(15.6)$ & $2.74(1.22 \text { to } 6.14)^{b}$ & 0.049 \\
\hline NICU admission & $84(24.3)$ & $148(31.6)$ & $1.42(1.04$ to 1.95$)$ & $20(31.3)$ & $1.28(0.70$ to 2.32$)$ & 0.091 \\
\hline Sepsis & $53(15.5)$ & $57(12.4)$ & 0.79 (0.53 to 1.19$)$ & $11(18.0)$ & $1.20(0.58$ to 2.49$)$ & 0.36 \\
\hline Death & $3(0.9)$ & $6(1.3)$ & NA & 0 & NA & NA \\
\hline
\end{tabular}

a. b identify the significant pairwise post-hoc comparisons with reference group (NGWG) after Bonferroni's correction.

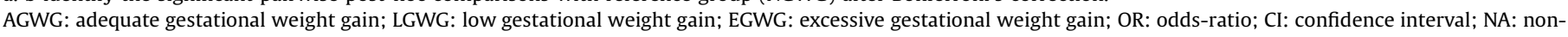
applicable; PROM: premature rupture of membranes ( $>12 \mathrm{~h}$; at any gestational age); IUGR: intra uterine growth restriction; NICU: neonatal intensive care unit.

P-value for global comparison between the three groups adjusted for pre-gestational BMI and smoking.

confirmed the findings of previous studies [11,15,17,18,24]. Nevertheless, it is uncertain why pre-pregnancy underweight and insufficient GWG could provoke preterm birth. Chronic nutritional deficiency and gestational anemia lead to placenta dysfunction, which is considered to lead to the production of stress hormones, thus promoting uterine contractions. Deficiencies in nutrients involved in the immune system (iron, zinc), could also be involved in an enhancement of infections, known to carry for preterm births.

We found that hypertensive gestational disorders were associated with excessive GWG, as demonstrated for singletons [43]. The mechanisms are poorly understood, but they may involve hypertriglyceridemia, elevation of fatty acids, and increased fraction of low density lipoprotein-cholesterol, making women atherogenic and bringing about endothelial dysfunction [44]. It is difficult to specify whether weight gain induces the occurrence of vascular complications or if, conversely, weight gain is the consequence of a frequent fluid-sodium retention in the case of preeclampsia or pregnancy-induced hypertension.

We did not find a link between GWG and gestational diabetes. Past studies have reported contradictory associations, and only in specific BMI subgroups $[18,19,31,32]$, making their results difficult to interpret. For singletons, the IOM concluded in 2009 that the available data (11 studies) provided weak evidence of a link between GWG and development of an abnormal glucose metabolism [13].

The main interest of our study was the detailed report of neonatal outcomes and the highlighting of a statistically significant impact of GWG on those outcomes (more respiratory distress in LGWG group and more Apgar scores $<7$ at 5 min in EGWG group), which has been poorly reported to date. Transfer to the NICU was also more frequent LGWG group, even if the difference did not reach the statistically significance (31.6\% vs. $24.3 \%)$.

Indeed, among the available studies on GWG and twin gestations according to the IOM guidelines, only a small body of data is available. Fox et al. and Lal et al. reported on NICU admissions [16,31], while Gavard et al. reported on Apgar scores and first-year mortality [23]. None of these studies found any significant difference. For Gavard et al., this can be attributed to the exclusive inclusion of obese women, as obesity is a major overwhelming factor. For the 2 other studies, we cannot exclude practice differences. Indeed, Lal et al. found that around $45 \%$ of the pregnancies resulted in NICU admissions, which is more than in our cohort, while Fox et al. found around 3\%, mostly because they did not include preterm births.

The limitations of this study mainly related to its retrospective design and the rate of excluded patients. The exclusion rate was high (32\%) because we decided to exclude all the patients for whom we did not have any GWG data from less than 1 month before delivery, and even if these data are part of the recommended monthly prenatal consultation, they were often missing. The advantage is that we are showing these data; we did not choose to avoid including them, leaving the data unavailability rate unknown. In addition, we showed that the included and excluded patient characteristics were not statistically different (Table 3, Supplementeray material). Finally, we decided not to adjust for chorionicity, as suggested in the literature [26], but we showed in Table 1 than chorionicity was equally distributed in the different groups.

\section{Conclusion}

Our results suggest that the 2009 IOM guidelines for twin pregnancy are appropriate and therefore should be routinely used to improve twin pregnancies outcomes. The finding that a focus on nutrition and adequate weight gain may prolong twin gestations is exciting. Even if there is no prospective trial in this field yet, all the retrospective data are tending toward the same results.

In any case, nutritional assessment and counseling need to be part of twin pregnancies' prenatal care, as gestational weight gain is a modifiable factor.

\section{Declaration of interests}

The authors report no conflict of interest.

\section{Appendix A. Supplementary data}

Supplementary material related to this article can be found, in the online version, at doi:https://doi.org/10.1016/j.ejogrb.2019.01.010. 


\section{References}

[1] Chauhan SP, Scardo JA, Hayes E, Abuhamad AZ, Berghella V. Twins: prevalence, problems, and preterm births. Am J Obstet Gynecol 2010;203(October (4)):305-15.

[2] Kogan MD, Alexander GR, Kotelchuck M, MacDorman MF, Buekens P, Martin $\mathrm{JA}$, et al. Trends in twin birth outcomes and prenatal care utilization in the United States, 1981-1997. JAMA 2000;284(3):335-41.

[3] Martin JA, Hamilton BE, Ventura SJ, Osterman MJK, Kirmeyer S, Mathews TJ, et al. Births: final data for 2009. Natl Vital Stat Rep 2011;60(1):1-70.

[4] Macdorman MF, Kirmeyer S. The challenge of fetal mortality. NCHS Data Brief 2009; (April (16)):1-8.

[5] Blondel B, Macfarlane A, Gissler M, Breart G, Zeitlin J, PERISTAT Study Group. Preterm birth and multiple pregnancy in European countries participating in the PERISTAT project. BJOG Int J Obstet Gynaecol 2006;113(5):528-35.

[6] Olson CM. A call for intervention in pregnancy to prevent maternal and child obesity. Am J Prev Med 2007;33(5):435-6.

[7] Oken E. Maternal and child obesity: the causal link. Obstet Gynecol Clin N Am 2009;36(2)361-77 ix-x.

[8] Viswanathan M, Siega-Riz AM, Moos MK, Deierlein A, Mumford S, Knaack J, et al. Outcomes of maternal weight gain. Evid Rep Technol Assess 2008; (168):1-223.

[9] Morikawa M, Yamada T, Akaishi R, Yamada T, Nishida R, Sato S, et al. Gestational weight gain according to number of fetuses in Japanese women. J Perinat Med 2014;42(4):523-8.

[10] Suitor CW. Perspectives on nutrition during pregnancy: part I, weight gain; part II, nutrient supplements. J Am Diet Assoc 1991;91(1):96-8.

[11] Chu SY, D’Angelo DV. Gestational weight gain among US women who deliver twins, 2001-2006. Am J Obstet Gynecol 2009;200(April (4))390 e1-6.

[12] Luke B, Hediger ML, Nugent C, Newman RB, Mauldin JG, Witter FR, et al. Body mass index-specific weight gains associated with optimal birth weights in twin pregnancies. J Reprod Med 2003;48(4):217-24.

[13] Institute of Medicine (US) and National Research Council (US) Committee to Reexamine IOM Pregnancy Weight Guidelines. In: Rasmussen KM, Yaktine AL, editors. Weight gain during pregnancy: reexamining the guidelines. Washington (DC): National Academies Press (US); 2009. . [Internet] [cité 20 juin 2016]. (The National Academies Collection: Reports funded by National Institutes of Health). Disponible sur: http://www.ncbi.nlm.nih.gov/books/ NBK32813/.

[14] American College of Obstetricians and Gynecologists. ACOG committee opinion no. 548: weight gain during pregnancy. Obstet Gynecol 2013;121 (1):210-2.

[15] Fox NS, Rebarber A, Roman AS, Klauser CK, Peress D, Saltzman DH. Weight gain in twin pregnancies and adverse outcomes: examining the 2009 Institute of Medicine guidelines. Obstet Gynecol 2010;116(1):100-6.

[16] Fox NS, Saltzman DH, Kurtz H, Rebarber A. Excessive weight gain in term twin pregnancies: examining the 2009 Institute of Medicine definitions. Obstet Gynecol 2011;118(November (5)):1000-4.

[17] Shamshirsaz AA, Haeri S, Ravangard SF, Sangi-Haghpeykar H, Gandhi M, Ozhand A, et al. Perinatal outcomes based on the institute of medicine guidelines for weight gain in twin pregnancies. J Matern-Fetal Neonatal Med 2014;27(April (6)):552-6.

[18] González-Quintero VH, Kathiresan ASQ, Tudela FJ, Rhea D, Desch C, Istwan N. The association of gestational weight gain per institute of medicine guidelines and prepregnancy body mass index on outcomes of twin pregnancies. Am J Perinatol 2012;29(6):435-40.

[19] Pettit KE, Lacoursiere DY, Schrimmer DB, Alblewi H, Moore TR, Ramos GA. The association of inadequate mid-pregnancy weight gain and preterm birth in twin pregnancies. J Perinatol 2015;35(2):85-9.

[20] Pécheux O, Garabedian C, Mizrahi S, Cordiez S, Deltombe S, Deruelle P. Maternal and neonatal outcomes according to gestational weight gain in twin pregnancies: are the IOM guidelines associated with better issues? Gynecol Obstet Fertil Senol 2017;45(6):366-72.

[21] Colletto GMDD, Segre CAM. Lack of effect of maternal body mass index on anthropometric characteristics of newborns in twin gestations. Genet Mol Res GMR 2005;4(1):47-54.
[22] Pederson AL, Worthington-Roberts B, Hickok DE. Weight gain patterns during twin gestation. J Am Diet Assoc 1989;89(5):642-6.

[23] Gavard JA, Artal R. Gestational weight gain and maternal and neonatal outcomes in term twin pregnancies in obese women. Twin Res Hum Genet 2014;17(2):127-33.

[24] Gonzalez-Ojeda A, Rodriguez-Alcantar DA, Arenas-Marquez H, Sanchez PerezVerdia E, Chavez-Perez R, Alvarez-Quintero R, et al. Retained foreign bodies following intra-abdominal surgery. Hepatogastroenterology 1999;46 (26):808-12.

[25] Schwendemann WD, O’Brien JM, Barton JR, Milligan DA, Istwan N. Modifiable risk factors for growth restriction in twin pregnancies. Am J Obstet Gynecol 2005;192(5):1440-2.

[26] Bodnar LM, Pugh SJ, Abrams B, Himes KP, Hutcheon JA. Gestational weight gain in twin pregnancies and maternal and child health: a systematic review. J Perinatol 2014;34(April (4)):252-63.

[27] Leese B, Jomeen J, Denton J. Appropriate maternal weight gain in singleton and twin pregnancies: what is the evidence? Hum Fertil Camb Engl 2012;15(4):194-9.

[28] Phelan S, Phipps MG, Abrams B, Darroch F, Schaffner A, Wing RR. Practitioner advice and gestational weight gain. J Womens Health 2011;20(4)585-91 2002.

[29] Phelan S, Phipps MG, Abrams B, Darroch F, Schaffner A, Wing RR. Randomized trial of a behavioral intervention to prevent excessive gestational weight gain: the Fit for Delivery Study. Am J Clin Nutr 2011;93(4):772-9.

[30] Hui A, Back L, Ludwig S, Gardiner P, Sevenhuysen G, Dean H, et al. Lifestyle intervention on diet and exercise reduced excessive gestational weight gain in pregnant women under a randomised controlled trial. BJOG Int J Obstet Gynaecol 2012;119(January (1)):70-7.

[31] Hruby A, Hu FB. The epidemiology of obesity: a big picture. Pharmacoeconomics 2015;33(July (7)):673-89.

[32] Stevens GA, Singh GM, Lu Y, Danaei G, Lin JK, Finucane MM, et al. National, regional, and global trends in adult overweight and obesity prevalences. Popul Health Metrics 2012;10(1):22.

[33] Lal AK, Kominiarek MA. Weight gain in twin gestations: are the Institute of Medicine guidelines optimal for neonatal outcomes? J Perinatol 2015;35 (6):405-10.

[34] Ozcan T, Bacak SJ, Zozzaro-Smith P, Li D, Sagcan S, Seligman N, et al. Assessing weight gain by the 2009 Institute of Medicine guidelines and perinatal outcomes in twin pregnancy. Matern Child Health J 2017;21(3):509-15.

[35] Vayssière C, Benoist G, Blondel B, Deruelle P, Favre R, Gallot D, et al. Twin pregnancies: guidelines for clinical practice from the French College of Gynaecologists and Obstetricians (CNGOF). Eur J Obstet Gynecol Reprod Biol $2011 ; 156(1): 12-7$.

[36] ACOG Committee on Practice Bulletins-Obstetrics. ACOG practice bulletin. Diagnosis and management of preeclampsia and eclampsia. Number 33 , January 2002. Obstet Gynecol 2002;99(1):159-67.

[37] Leroy B, Lefort F, Neveu P, Risse RJ, Trévise P, Jeny R. Intrauterine growth charts for twin fetuses. Acta Genet Med Gemellol (Roma) 1982;31(3-4):199-206.

[38] McKeating A, Maguire PJ, Daly N, Farren M, McMahon L, Turner MJ. Trends in maternal obesity in a large university hospital 2009-2013. Acta Obstet Gynecol Scand 2015;94(September (9)):969-75.

[39] Ng M, Fleming T, Robinson M, Thomson B, Graetz N, Margono C, et al. Global, regional, and national prevalence of overweight and obesity in children and adults during 1980-2013: a systematic analysis for the Global Burden of Disease Study 2013. Lancet Lond Engl 2014;384(9945):766-81.

[40] Matta J, Carette C, Rives Lange C, Czernichow S. French and worldwide epidemiology of obesity. Presse Med Paris Fr 1983 2018;47(5):434-8.

[41] Bohni S, Roos M, Kurmanavicius J, Zimmermann R, Ochsenbein-Kolble N. New reference curves on maternal weight gain in twin pregnancy. Geburtshilfe und Frauenheilkunde 2011;71(11):979-84.

[42] Lantz ME, Chez RA, Rodriguez A, Porter KB. Maternal weight gain patterns and birth weight outcome in twin gestation. Obstet Gynecol 1996;87(April (4)):551-6.

[43] Ruhstaller KE, Bastek JA, Thomas A, Mcelrath TF, Parry SI, Durnwald CP. The effect of early excessive weight gain on the development of hypertension in pregnancy. Am J Perinatol 2016;33(12):1205-10.

[44] Sattar N, Bendomir A, Berry C, Shepherd J, Greer IA, Packard CJ. Lipoprotein subfraction concentrations in preeclampsia: pathogenic parallels to atherosclerosis. Obstet Gynecol 1997;89(3):403-8. 